JHR

36,3

Received 4 June 2020

Revised 7 August 2020 21 September 2020

Accepted 7 October 2020

\section{Chronic health conditions, healthcare experience and life satisfaction among immigrant and native-born women in Canada}

\author{
Yiyan Li and Siyu Ru \\ University of Saskatchewan, Saskatoon, Canada
}

\begin{abstract}
Purpose - To compare chronic health status, utilization of healthcare services and life satisfaction among immigrant women and their Canadian counterparts.

Design/methodology/approach - A secondary analysis of national data from the Canadian Community Health Survey (CCHS), 2015-2016 was conducted. The survey data included 109,659 cases. Given the research question, only female cases were selected, which resulted in a final sample of 52,560 cases. Data analysis was conducted using multiple methods, including logistic regression and linear regression.

Findings - Recent and established immigrant women were healthier than native-born Canadian women. While the Healthy Immigrant Effect (HIE) was evident among immigrant women, some characteristics related to ethnic origin and/or unhealthy dietary habits may deteriorate immigrant women's health in the long term. Immigrant women and non-immigrant women with chronic illnesses were both more likely to increase their use of the healthcare system. Notably, the present study did not find evidence that immigrant women under-utilized Canada's healthcare system. However, the findings showed that chronic health issues were more likely to decrease women's life satisfaction.

Originality/value - This analysis contributes to the understanding of immigrant women's acculturation by comparing types of chronic illnesses, healthcare visits, and life satisfaction between immigrant women and their Canadian counterparts.
\end{abstract}

Keywords Immigrant women, Chronic illness, Healthcare services, Life satisfaction, Canada

Paper type Research paper

\section{Introduction}

Immigrants comprise a significant component of Canadian society, as more than $20 \%$ of the Canadian population was born overseas [1]. Compared to their male counterparts, female immigrants are left behind in many areas, such as in civic participation, income, health and access to healthcare [1]. Given that the wellbeing of immigrants and refugees is an important goal of the Government of Canada [2], this work will compare immigrant women and nativeborn Canadian women with respect to chronic health status, health care system use and life satisfaction.

The existing literature suggests that immigrants' health status is related to the healthy immigrant effect (HIE). The HIE posits that immigrants, and recent immigrants, have a health advantage in their receiving countries due to being generally healthier than the native-born population [2-5]. This is supported by Newbold's [4] comparison of the health status of immigrants and non-immigrants which showed that recent immigrants were likely to be healthier than their Canadian counterparts in terms of chronic health status. One potential

(C) Yiyan Li and Siyu Ru. Published in Journal of Health Research. Published by Emerald Publishing Limited. This article is published under the Creative Commons Attribution (CC BY 4.0) licence. Anyone may reproduce, distribute, translate and create derivative works of this article (for both commercial and non-commercial purposes), subject to full attribution to the original publication and authors. The full terms of this licence may be seen at http://creativecommons.org/licences/by/4.0/legalcode 
reason for the HIE is the immigration screening process, as countries generally tend to admit immigrants who are in good health. However, after several years in their new country, immigrants tend to experience a decline in health, with some developing chronic diseases or disabilities $[2,4,5]$. Since health conditions are related to one's social environment and wellbeing, it would be useful to explore how these factors impact chronic health conditions in immigrant and non-immigrant women.

Researchers have defined chronic health issues in different ways. Newbold [4] defines chronic health conditions as physical illnesses such as heart disease, diabetes, asthma, and arthritis. While many studies have similarly defined chronic health issues in terms of physical diseases. Cameron [6] has recently argued that physical and mental health issues are connected. This more holistic conception of chronic health issues was previously advanced by Beiser and Hou [2], whose definition of chronic diseases included physical and mental conditions such as asthma, arthritis, back problems, high blood pressure, migraine headaches, chronic bronchitis, emphysema or COPD, diabetes, heart disease, cancer, stomach or intestinal ulcers, the effects of a stroke, urinary incontinence, bowel disorders, mood disorders and anxiety disorders. Given that immigrant women may have a higher risk of experiencing mental or physical disorders, this study employs a definition of chronic health conditions that include both physical and mental health.

Accessing and navigating the healthcare system can be a challenging process for immigrants, especially for immigrant women [5]. These challenges have led to the underutilization of the healthcare system by immigrants, and, this underutilization has emerged as a health and equality issue [7]. According to HIE, immigrants may use healthcare services more frequently the longer they are in their adopted country, and as their health declines with age. Beiser and Hou [2] surveyed whether people had visited a physician in the past 12 months, finding that established immigrants with chronic diseases and their native-born Canadian counterparts were more likely to visit a doctor than were recent immigrants with chronic illnesses. Notably, many studies have also found that immigrant women are less likely than immigrant men to use healthcare services $[5,8,9]$.

Although chronic health conditions may not necessarily increase immigrants' use of healthcare services, they are more likely to face barriers to accessing the host country's healthcare system compared to non-immigrants. Due to their roles as family caregivers and lower incomes, immigrant women may neglect their health status and attempt to access fewer healthcare services [8]. Furthermore, lower language proficiency and shorter lengths of residence may also lower immigrant women's likelihood of accessing healthcare services $[2,7]$. Beiser and Hou [2] found that age and educational background influenced an immigrants' likelihood of accessing healthcare services, with immigrants in Alberta and Quebec being the least likely to visit health clinics. This study examined a range of factors, including language ability, length of residence, age, education, geography, marital status, income, and employment status, and aimed to assess: (a) whether and to what degree these factors influence immigrant women's likelihood to access healthcare services; and (b) how the healthcare experiences of immigrant women differ from those of non-immigrant women. The purpose of this study, healthcare system usage, was measured by visits to clinics or doctors $[2,5]$.

Life satisfaction is important for immigrants, as it is a reflection of not only their subjective wellbeing, but also their acculturation in their adopted society [10]. Life satisfaction is influenced by socioeconomic status, health, age and marital status [11]; however, some researchers have argued that employment and health are the strongest predictors of life satisfaction [12]. Indeed, Premji and Shakya's [12] interviews with 30 immigrant women living in Toronto revealed that unemployment had a negative impact on the respondents' 
JHR

36,3

health and subjective wellbeing. On the other hand, Grewal et al. [13] have argued that being able and willing to access the healthcare system yields significant benefits for immigrant women's well-being. Given the importance of wellbeing, it is necessary to examine which factors influence wellbeing among immigrant women and native-born Canadian women.

To date, very few studies have examined the differences in outcomes between immigrant and non-immigrant women, especially in relation to health and wellbeing. The present work examines how chronic disease and an assortment of demographic factors influence healthcare service usage and life satisfaction among immigrant women and native-born Canadian women.

\section{Methods}

\section{Study sample}

This study uses data from the 2015-2016 Canadian Community Health Survey (CCHS), which was the most recent available dataset at the time this research was initiated. The dataset was accessed through the library at the University of Saskatchewan. According to the license information on the library's website [14], this dataset is available to current students, faculty, and staff of the University of Saskatchewan for research purposes.

The CCHS is a cross-sectional survey that provides information on health status, healthcare utilization, health determinants, and demographic characteristics. The CCHS aims to "support local health units by providing them with the timely information they need to evaluate existing programs and to design new ones suited to their community" and to "provide more current, detailed and uniform health information in every province and territory" [15]. The survey results can be used to address emerging health issues, and to inform "policy-making and program development that affect Canadian communities" [15]. The 2015-2016 CCHS used a multi-stage sampling strategy to recruit respondents, with individuals 12 years of age and older living in Canada's ten provinces and three territories being eligible to participate in the survey. Data collection was conducted via computerassisted telephone interviews (CATI) and computer-assisted personal interviews (CAPI). The 2015-2016 CCHS had an overall response rate of $61.3 \%$.

The study used logistic regression and multiple linear regression to examine differences in health conditions, health-services utilization, and life satisfaction among adult immigrant and non-immigrant women (i.e. $>18$ years). Demographic and socioeconomic characteristics were used as control variables in the regression models, with Stata 14 being used for data analysis. The variables are introduced in the next section.

\section{Study measures}

Because this study focused on adult women, female respondents younger than 18 years old and male participants were dropped from the dataset. The rest of the respondents were classified into three groups: recent immigrant women (residing in Canada for less than 10 years); established immigrant women (residing in Canada for 10 years or more); and nativeborn women. Logistic regression was used to investigate whether health conditions and healthcare service usage rates differed among the three groups of women, while multiple linear regression was used to compare life satisfaction among immigrant and non-immigrant women with and without chronic conditions.

This study examines the HIE by investigating whether immigrant women have fewer chronic conditions than native-born women. In this study, the term, chronic conditions, encompasses a range of physical and mental ailments, including asthma, COPD, scoliosis, fibromyalgia, arthritis, back problems, osteoporosis, high blood pressure, high blood cholesterol/lipids, heart disease, effects of a stroke, diabetes, cancer, headaches, multiple 
chemical sensitivities, mood disorder (depression, bipolar, mania, dysthymia) and anxiety disorder (phobia, OCD, panic). The CCHS included a number of questions relating to these conditions, for example, "do you have asthma?" and "do you have diabetes?" with participant responses being coded as either No (0) or Yes (1). Participants who answered "yes" to having diabetes and/or cancer were further asked whether their condition had been formally diagnosed by a medical doctor. For the rest of the health conditions, participants were not required to specify whether an official diagnosis had been made by a medical doctor. Given the CCHS's reliance on self-reporting, the dataset may not be an accurate reflection of the participants' actual health conditions, which is a potential limitation of this study. For the purposes of this research, we created a general dummy variable: chronic conditions. All participants who answered "yes" to any of the questions related to chronic conditions above coded as having a chronic condition (1), while those who answered "no" to all of the questions were classified as having no chronic conditions (0). For the new chronic conditions variable, there were 17,513 missing cases.

The other outcome variables examined in this research were healthcare service usage and general life satisfaction. Healthcare service usage was measured using the survey question: "In the past 12 months, have you seen or talked to any of the following health professionals about your physical, emotional, or mental health: a family doctor /pediatrician or a general practitioner?" Participants were required to provide a Yes (1) or No (0) response to this question. General life satisfaction was measured using a five-point scale, with 1 indicating "very dissatisfied" and 5 indicating "very satisfied." The mean score for life satisfaction among women living in Canada was 4.29.

Demographic characteristics included the following categories: (1) Age divided into four groups: 18-24 years, 25-44 years, 45-64 years, and 65 and older; (2) Marital status containing three categories: married/common-law, widowed/divorced/separated, and single; (3) Income measured by total household income: less than $\$ 39,999, \$ 40,000-\$ 79,999$, and $\$ 80,000$ or more; (4) Employment status classified into two groups: employed and unemployed; (5) Educational background divided into three categories: less than secondary school graduation, secondary school graduation, and post-secondary certificate diploma; (6) Official language ability as a dummy variable to measure the respondent's ability to conduct a conversation in English or French; (7) Geographic region coded into six groups: Eastern (Newfoundland and Labrador, Prince Edward Island, Nova Scotia, New Brunswick), Quebec, Ontario, Prairies (Manitoba, Saskatchewan, Alberta), British Columbia, and Territories (Yukon, Northwest Territories, Nunavut). It should be noted that we re-coded the income variable, as the 2015-2016 CCHS originally classified household income into five groups (no income or less than $\$ 20,000 ; \$ 20,000$ to $\$ 39,999$; $\$ 40,000$ to $\$ 59,999 ; \$ 60,000$ to $\$ 79,999 ; \$ 80,000$ or more). According to Statistics Canada, in 2015 , the median household income after tax was $\$ 61,348$ [16]. The Organization for Economic Co-operation and Development (OECD) defines the middle class as those who earn between three-quarters and double the median household income after tax. Based on the data available from Statistics Canada, Canada's middle class includes households that earn between $\$ 46,011$ and $\$ 122,696$ after tax. Using this data, we re-coded household income into three groups: low income $(\$ 0-\$ 39,999)$, middle income $(\$ 40,000-\$ 79,999)$, and high income $(\$ 80,000+)$.

\section{Ethical considerations}

According to the Ethics Office at the University of Saskatchewan, research involving human subjects must receive human ethics approval by a Research Ethics Board prior to commencement [17]. However, research using publicly available reports, literature, or Statistics Canada data does not require review and approval. 


\section{Results}

Demographic characteristics

Demographic information for the native-born women, recent immigrant women, and established immigrant women were examined in this study (Table 1). On average, recent immigrant women were younger and had higher levels of education than their established or native-born counterparts. The distribution of their household income was similar to nativeborn women, with about $30 \%$ of the respondents reporting low annual incomes.

Comparative general health condition, healthcare service use, and life satisfaction

The differences in general chronic health conditions, doctor visits, and life satisfaction among the three groups of women were compared (Table 2). Recent immigrant women were much less

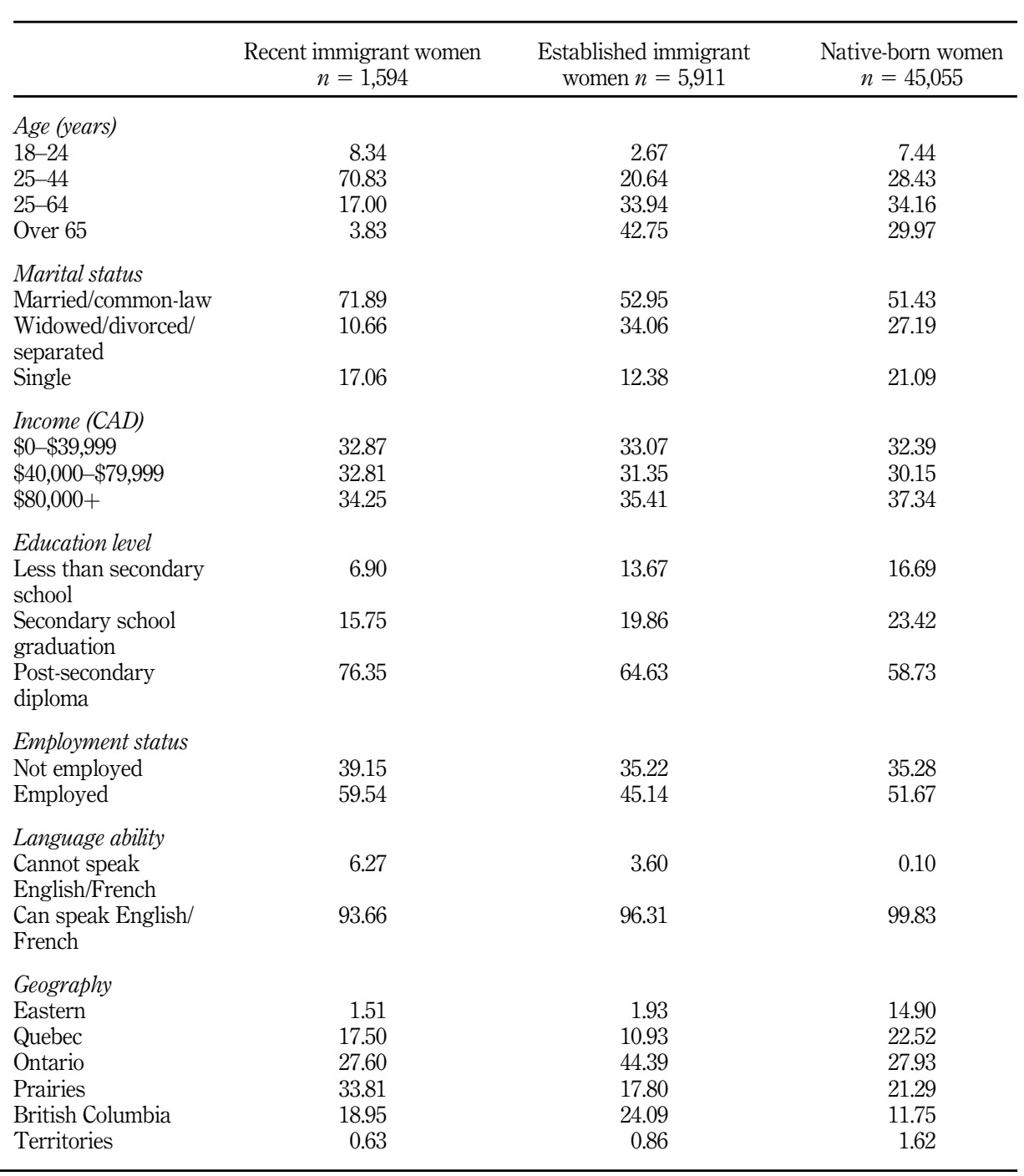

Table 1.

Demographic characteristics: Canadian community health survey (2015-2016) 
likely to have chronic health conditions than their established and native-born counterparts. Although most of the participants reported visiting a health professional in the past 12 months, established immigrant women and native-born women were more likely to have used healthcare services during this period. All respondents reported a high level of general life satisfaction (total score $=5$ ), with recent immigrant women having a higher average score.

\section{Comparative chronic conditions}

Whether native-born, recent immigrant, and established immigrant women experiencing different chronic conditions were investigated (Table 3). In general, immigrant women tended to have better overall health than their established and native-born counterparts, including both physical and mental health. As shown in Table 3, immigrant women were significantly less likely to have asthma, COPD, scoliosis, arthritis, back problems, mood disorders, and anxiety disorder. On the other hand, established immigrant women faced a higher risk of having high blood cholesterol/lipids and diabetes, and they were significantly more likely to have high blood pressure and diabetes compared to recent immigrant and native-born women.

\begin{tabular}{|c|c|c|c|}
\hline & $\begin{array}{l}\text { Recent immigrant women } \\
\qquad n=1,594\end{array}$ & $\begin{array}{l}\text { Established immigrant women } \\
\qquad n=5,911\end{array}$ & $\begin{array}{c}\text { Native-born women } \\
n=45,055\end{array}$ \\
\hline \multicolumn{4}{|c|}{ Chronic conditions* } \\
\hline Yes & 18.38 & 60.46 & 52.86 \\
\hline No & 16.37 & 19.07 & 14.75 \\
\hline \multicolumn{4}{|c|}{ Healthcare service use last year } \\
\hline Yes & 67.44 & 79.04 & 76.61 \\
\hline No & 32.37 & 20.76 & 23.22 \\
\hline Life & 4.32 & 4.24 & 4.29 \\
\hline
\end{tabular}

Note(s): *There were 17,513 missing values in the variable of chronic conditions

Table 2 .

Comparative general health condition, healthcare service use and life satisfaction, Canadian community health survey

(2015-2016)

\begin{tabular}{lcc}
\hline & Recent immigrants & Established immigrants \\
\hline Asthma & $-1.15^{* * * *}$ & $-0.38^{* * *}$ \\
COPD & $-1.60^{* * * *}$ & $-0.94^{* * *}$ \\
Scoliosis & $-0.71^{* *}$ & $-0.34^{* * *}$ \\
Fibromyalgia & $-1.56^{* * *}$ & $-0.29^{*}$ \\
Arthritis & $-0.98^{* * *}$ & $-0.27^{* * *}$ \\
Back problems & $-0.42^{* * *}$ & -0.01 \\
Osteoporosis & -0.27 & 0.10 \\
High blood pressure & -0.19 & $0.13^{*}$ \\
High blood cholesterol/lipids & $0.33^{* *}$ & $0.32^{* * *}$ \\
Heart disease & -0.60 & -0.20 \\
The effects of stroke & -0.96 & -0.15 \\
Diabetes & 0.11 & $0.32^{* * *}$ \\
Cancer & -0.57 & -0.0004 \\
Headaches & -0.14 & 0.04 \\
Chemical sensitivities & -0.01 & -0.16 \\
Mood disorder & $-1.21^{* * *}$ & $-0.46^{* * *}$ \\
Anxiety disorder & $-1.33^{* * *}$ & $-0.62^{* * *}$ \\
Note(s): The oddl & -1. &
\end{tabular}

Note(s): The odds ratios are estimated from logistic regression models with age as the control group. $*$ Significant at $p<0.05, * * p<0.01, * * * p<0.001$
Table 3.

Comparative Chronic Conditions (nativeborn women as the reference group), Canadian community health survey (2015-2016) 
JHR

36,3

468
Testing healthcare service use and general life satisfaction

Odds ratios from the logistic regression model testing the relationship between healthcare service use and the prevalence of chronic conditions among the different groups of women are shown in Table 4. The multiple regression model results examining the effects of chronic conditions and immigrant status on general life satisfaction are presented (Table 5). The first column in both tables lists the predictive variables (Tables 4 and 5). The reference groups for both tables consist of the following: native-born women who have no chronic conditions; women who are younger than 45 years old; women who are married/common-law; women with lower income and education levels; unemployed women; women who are unable to speak one of Canada's two official languages; and women who live in the Eastern region (Newfoundland and Labrador, Prince Edward Island, Nova Scotia, New Brunswick).

\section{Healthcare service use}

Model 1 in Table 4 shows that compared with native-born Canadian women with no chronic conditions, those with chronic conditions were significantly more likely to use healthcare services. After controlling other demographic characteristics in Model 2, the results changed slightly. Compared with healthy native-born Canadian women, healthy recent immigrant women were less likely, and healthy established immigrant women were more likely to see doctors, but these two results were not statistically significant after controlling other demographic characteristics. Those with chronic conditions, no matter native-born women, recent immigrant women, and established immigrant women, were more likely to visit health professionals than native-born women without chronic conditions.

\begin{tabular}{|c|c|c|c|c|c|c|}
\hline \multirow[b]{3}{*}{ Native-born women, with chronic conditions } & \multicolumn{6}{|c|}{ Healthcare service use } \\
\hline & \multirow{2}{*}{$\begin{array}{r}\text { M } \\
\text { Odds ratio } \\
0.93^{* * *}\end{array}$} & \multicolumn{2}{|c|}{$\begin{array}{c}\text { odel } 1 \\
95 \% \\
\text { confident } \\
\text { interval }\end{array}$} & \multirow{2}{*}{$\frac{\text { Odds ratio }}{0.98^{* * * *}}$} & \multicolumn{2}{|c|}{$\begin{array}{l}\text { Aodel } 2 \\
\begin{array}{l}\text { 95\% confident } \\
\text { interval }\end{array}\end{array}$} \\
\hline & & 0.82 & 1.04 & & 0.87 & 1.10 \\
\hline Recent immigrant women, no chronic conditions & -0.20 & -0.63 & 0.22 & -0.22 & -0.66 & 0.22 \\
\hline $\begin{array}{l}\text { Recent immigrant women, with chronic } \\
\text { conditions }\end{array}$ & $0.55^{* *}$ & 0.16 & 0.94 & $0.46^{*}$ & 0.05 & 0.88 \\
\hline $\begin{array}{l}\text { Established immigrant women, no chronic } \\
\text { conditions }\end{array}$ & 0.03 & -0.20 & 0.26 & 0.04 & -0.20 & 0.29 \\
\hline $\begin{array}{l}\text { Established immigrant women, with chronic } \\
\text { conditions }\end{array}$ & $1.05^{* * * *}$ & 0.87 & 1.24 & $0.99 * * *$ & 0.78 & 1.21 \\
\hline 45-64 years old & & & & 0.09 & -0.06 & 0.24 \\
\hline Over 65 years old & & & & 0.11 & -0.07 & 0.30 \\
\hline Widowed/divorced/separated & & & & 0.04 & -0.11 & 0.18 \\
\hline Single & & & & $-0.19 *$ & -0.37 & -0.01 \\
\hline$\$ 40,000-\$ 79,000$ & & & & 0.14 & -0.01 & 0.28 \\
\hline$\$ 80,000+$ & & & & $0.32 * * *$ & 0.16 & 0.48 \\
\hline Secondary school graduation & & & & 0.07 & -0.11 & 0.25 \\
\hline Post-secondary diploma & & & & $0.34^{* * * *}$ & 0.17 & 0.50 \\
\hline Employed & & & & $-0.13^{*}$ & -0.26 & -0.01 \\
\hline Able to speak English/French & & & & -0.55 & -1.14 & 0.04 \\
\hline Quebec & & & & $-0.65^{* * *}$ & -0.80 & -0.50 \\
\hline Ontario & & & & $-0.34 * * *$ & -0.49 & -0.18 \\
\hline Prairies & & & & -0.04 & -0.21 & 0.12 \\
\hline British Columbia & & & & 0.004 & -0.19 & 0.19 \\
\hline Territories & & & & $-0.81^{* * *}$ & -1.15 & -0.46 \\
\hline$R$-square & 0.03 & & & 0.05 & & \\
\hline Note(s): *Significant at $p<0.05, * * p<0.01$, * & $<0.001$ & & & & & \\
\hline
\end{tabular}

\footnotetext{
Note(s): *Significant at $p<0.05, * * p<0.01, * * * p<0.001$
}

\section{Table 4.}

Logistic regression model examining the effects of chronic conditions and healthcare service use Canadian community health survey (2015-2016) 


\begin{tabular}{|c|c|c|c|c|c|c|c|}
\hline \multirow[b]{5}{*}{ Native-born women (chronic conditions) } & \multicolumn{6}{|c|}{ Life satisfaction } & \multirow{4}{*}{$\begin{array}{r}\text { Healthcare } \\
\text { experience and } \\
\text { native-born } \\
\text { women }\end{array}$} \\
\hline & & Todel 3 & & & odel 4 & & \\
\hline & \multirow{3}{*}{$\begin{array}{c}\text { Coefficient } \\
-0.31^{* * * *}\end{array}$} & \multirow{2}{*}{\multicolumn{2}{|c|}{$\begin{array}{l}95 \% \text { confident } \\
\text { interval }\end{array}$}} & \multirow{3}{*}{$\frac{\text { Coefficient }}{-0.26 * * *}$} & \multirow{2}{*}{\multicolumn{2}{|c|}{$\begin{array}{l}95 \% \text { confident } \\
\text { interval } \\
\end{array}$}} & \\
\hline & & & & & & & \\
\hline & & -0.34 & -0.28 & & -0.29 & -0.23 & \\
\hline $\begin{array}{l}\text { Recent immigrant women (no chronic } \\
\text { conditions) }\end{array}$ & $-0.12^{*}$ & -0.24 & -0.02 & -0.02 & -0.13 & 0.09 & 469 \\
\hline $\begin{array}{l}\text { Recent immigrant women (chronic } \\
\text { conditions) }\end{array}$ & $-0.42^{* * *}$ & -0.54 & -0.30 & $-0.31 * * *$ & -0.43 & -0.19 & \\
\hline $\begin{array}{l}\text { Established immigrant women (no chronic } \\
\text { conditions) }\end{array}$ & $-0.11 * * *$ & -0.17 & -0.05 & $-0.09 * *$ & -0.15 & -0.03 & \\
\hline $\begin{array}{l}\text { Established immigrant women (chronic } \\
\text { conditions) }\end{array}$ & $-0.34 * * *$ & -0.38 & -0.29 & $-0.30 * * *$ & -0.35 & -0.25 & \\
\hline $45-64$ years & & & & $0.07 * *$ & 0.03 & 0.11 & \\
\hline Over 65 years & & & & $0.28 * * * *$ & 0.23 & 0.34 & \\
\hline Widowed/divorced/separated & & & & $-0.19 * * *$ & -0.23 & -0.15 & \\
\hline Single & & & & $-0.24 * * *$ & -0.31 & -0.17 & \\
\hline$\$ 40,000-\$ 79,000$ & & & & $0.19 * * *$ & 0.15 & 0.24 & \\
\hline$\$ 80,000+$ & & & & $0.28 * * *$ & 0.24 & 0.33 & \\
\hline Secondary school graduation & & & & $0.09 *$ & 0.01 & 0.17 & \\
\hline Post-secondary diploma & & & & $0.12^{* *}$ & 0.05 & 0.19 & \\
\hline Employed & & & & $0.10^{* * * *}$ & 0.06 & 0.14 & \\
\hline Able to speak English/French & & & & $0.16^{*}$ & 0.02 & 0.31 & \\
\hline Quebec & & & & $-0.04 *$ & -0.08 & 0.00 & \\
\hline Ontario & & & & $-0.08^{* *}$ & -0.12 & -0.03 & \\
\hline Prairies & & & & $-0.12^{* * * *}$ & -0.17 & -0.08 & $\begin{array}{l}\text { Multiple regression } \\
\text { mold axamining the }\end{array}$ \\
\hline British Columbia & & & & $-0.09 * * *$ & -0.14 & -0.04 & model examining the \\
\hline Territories & & & & -0.05 & -0.15 & 0.04 & $\begin{array}{l}\text { eftects of chronic } \\
\text { conditions oeneral life }\end{array}$ \\
\hline Health service use & & & & -0.04 & -0.08 & 0.01 & $\begin{array}{l}\text { conditions general lite } \\
\text { satisfaction, Canadian }\end{array}$ \\
\hline$R$-square & 0.03 & & & 0.10 & & & community health \\
\hline \multicolumn{7}{|c|}{ Note(s): *Significant at $p<0.05, * * p<0.01, * * * p<0.001$} & survey (2015-2016) \\
\hline
\end{tabular}

Aging was associated with an increased likelihood of doctor visits, but the results were not statistically significant. Women with a higher level of household annual income and education were more likely to use healthcare services in the past year. On the other hand, those who were singled, employed, and living in Quebec, Ontario, and territories had a significantly decreased likelihood of doctor visits.

\section{General life satisfaction}

Model 3 in Table 5 shows that native-born women with chronic conditions, recent immigrant women, and established immigrant women all had significantly lower levels of life satisfaction compared to native-born women with no chronic conditions. Although this gap narrowed when control variables were added in Model 4, native-born women without chronic conditions still had a higher level of life satisfaction. Thus, chronic conditions significantly influence life satisfaction, as the three groups of women with health issues all reported lower levels of life satisfaction.

Women who were not married or common-law, and who were living in Quebec, Ontario, British Columbia, and the Prairies, had lower levels of life satisfaction compared to those who were married/common-law or living in the Eastern region. Respondents who were able to speak one of the two official languages had higher life satisfaction than those who could not. Aging was positively associated with general life satisfaction: as age increased, so too did life satisfaction. Finally, women who had higher levels of education and income, as well as being employed, also had greater levels of life satisfaction. 
JHR

36,3

\section{Discussion}

Consistent with much of the research on the HIE [2, 4], our findings show that recent immigrant women tend to be healthier than native-born women and are less likely to have chronic health conditions than established immigrant women. However, since the CCHS is a cross-sectional survey, it cannot provide information that enables an examination of health changes in the same group of immigrant women. Thus, longitudinal research is needed to investigate the relationship between changes over time and immigrants' health status.

High blood pressure was an exception to the above finding, as established immigrant women were more likely to suffer from this condition compared to a recent immigrant and native-born women. This result is inconsistent with much previous research. For instance, Wong and Wong [18] analyzed data from the 1996 Canadian National Health Survey and found that visible minority immigrant women were less likely than White immigrant women to report some chronic illnesses, such as high blood pressure. Further research on the causes of the heightened risk of high blood pressure in immigrant women is needed.

Both recent and established immigrant women had higher rates of high blood cholesterol/ lipids than their native-born counterparts, while established immigrant women had higher rates of diabetes than recent immigrant and native-born women. A possible explanation for this result may be the interaction between multiple factors, such as the characteristics of some ethnic groups, such as genetic characteristics, lack of exercise, and unhealthy diets [19]. Given that the CCHS does not detail the reasons for the higher risk of these conditions, future research can focus on whether acculturation or particular lifestyles/eating habits rooted in different cultures may lead to these health issues.

The study found that both recent and established immigrant women are less likely to report mood and anxiety disorders, which is inconsistent with Beiser and Hou's findings [2]. One potential reason for this inconsistency may be that immigrant women are more likely to not recognize when they are experiencing mental health issues. Immigrant minority women may experience an array of stressful situations, such as dealing with immigration policies (e.g. family class sponsorship policy), in addition to having to deal with patriarchal norms, financial dependency and weak social capital, which may all negatively influence their mental health status [9]. Furthermore, immigrants from some cultures may be more reluctant to seek help when facing mental health issues. Given this, culturally sensitive and language-sensitive activities and programs may be very helpful in raising immigrant women's awareness of mental health issues [7].

In terms of the utilization of the healthcare system, our findings showed that immigrant women with chronic illnesses did not use fewer services than their established and nativeborn counterparts. In fact, chronic health issues were related to increased healthcare system use across all three groups of women. Although many previous studies have found that immigrant women tend to encounter many barriers to accessing healthcare services, and therefore use fewer services, the results of the present study aligned with Sethi's study [20], which raises the possibility that Canada's healthcare system has taken steps to promote immigrant women's use of healthcare services by offering culturally responsive approaches to service delivery. For example, Sethi [20] argued that immigrant women were more likely to visit mental health workers if the workers were able to speak their language. On the other hand, single immigrant and non-immigrant women residing in Quebec, Ontario, and the Territories were less likely to use healthcare services. However, women with high income and educational levels tended to use more health services, which aligns with Beiser and Hou's finding [2] that this demographic is more likely to use the healthcare system more frequently as a matter of health maintenance.

The study showed that all three groups of women had a relatively high level of life satisfaction, with recent immigrant women reporting higher levels (mean $=4.32$ ) than established immigrant women $($ mean $=4.24)$ and native-born women $($ mean $=4.29)$. This finding 
is consistent with Frank et al. [10], who found that, after migrating to Canada, immigrants from countries with low levels of economic development reported higher levels of life satisfaction compared to their source-country counterparts. Indeed, national wealth, human development, and environmental conditions are all key contributors to an individual's life satisfaction [11].

For both immigrant and non-immigrant women, chronic health status significantly predicted life satisfaction, which indicates that disease influences wellbeing. In addition, Bonini's [11] study of individual life satisfaction across countries showed that high income and employment are both important contributors to life satisfaction. In this sense, women with chronic health conditions may be limited in their ability to hold a job, which may have a deleterious effect on their level of life satisfaction [2]. Finally, the present study confirms that higher socioeconomic status is associated with higher levels of life satisfaction, as employment was strongly correlated with high levels of life satisfaction [11].

\section{Conclusions}

This analysis contributes to the understanding of immigrant women's acculturation by comparing immigrant and native-born women with respect to chronic illnesses, healthcare system use, and life satisfaction. In general, our results revealed that healthy immigrant women tended to have high levels of life satisfaction, and were not likely to use more healthcare services than healthy non-immigrant women. Due to the large sample used in this research (total number $=52,549$ ), we believe that our results are reliable and can be utilized to design health policies and programs aimed at promoting the wellbeing of immigrant women. However, questions related to immigrant women with chronic health issues remain unanswered. This study used data from the 2015-2016 CCHS to investigate the health conditions of immigrant and native-born women in Canada. Unfortunately, the data for chronic conditions in the CCHS are self-reported and, as such, may not be an accurate reflection of the participants' health status. This represents a key limitation when using secondary data. Previous research suggests that immigrant women are influenced by dual forces when making health-related choices: gender roles, and their ethnocultural background [7]. Immigrant women from different cultural backgrounds may employ different strategies for coping with chronic conditions; however, the dataset used in this study did not distinguish respondents by ethnic group. Thus, further research is needed to examine how ethnocultural factors influence immigrant women's health and their decision to use healthcare services.

Conflict of Interest: None

\section{References}

1. Li Y. Civic engagement and wellbeing among female immigrants in Canada. Can Ethn Stud. 2020; 52(1): 49-72. doi:10.1353/ces.2020.0006.

2. Beiser M, Hou F. Chronic health conditions, labour market participation and resource consumption among immigrant and native-born residents of Canada. Int J Public Health. 2014; 59(3): 541-7. doi: 10.1007/s00038-014-0544-z.

3. Kushniryk A, Titus-Roberts J, Wertz E. Immigration as a catalyst for increased health awareness: immigrant women define health and health decision making. J Immigr Refug Stud. 2014; 12(3): 172-90. doi: 10.1080/15562948.2013.826843.

4. Newbold KB. Chronic conditions and the healthy immigrant effect: evidence from Canadian immigrants. J Ethn Migr Stud. 2006; 32(5): 765-84. doi: 10.1080/13691830600704149.

5. Setia MS, Quesnel-Vallee A, Abrahamowicz M, Tousignant P, Lynch J. Access to health-care in Canadian immigrants: a longitudinal study of the national population health survey. Health Soc Care Community. 2011; 19(1): 70-9. doi: 10.1111/j.1365-2524.2010.00950.x. 
JHR

36,3
6. Cameron KA. Chronic conditions, from A to Z: life expectancy is lower in America than in other developed nations, mainly due to the toll of chronic conditions, many of which are preventable. Generations. 2019: Suppl 3: 8-12.

7. Fang L. A sociocultural perspective of mental health service use by Chinese immigrants. Can Soc Work. 2010; 12(1): 152-60.

8. Donnelly TT, McKellin W. Keeping healthy! Whose responsibility is it anyway? Vietnamese Canadian women and their healthcare providers' perspectives. Nurs Inq. 2007; 14(1): 2-12. doi: 10. 1111/j.1440-1800.2007.00347.x.

9. Sethi B. Health experiences of immigrant visible minority women: a literature review. J Evid Inf Soc Work. 2016; 13(6): 523-34. doi: 10.1080/23761407.2015.1089205.

10. Frank K, Hou F, Schellenberg G. Life satisfaction among recent immigrants in Canada: comparisons to source-country and host-country populations. J Happiness Stud. 2016; 17(4): 1659-80. doi: 10.1007/s10902-015-9664-2.

11. Bonini AN. Cross-national variation in individual life satisfaction: effects of national wealth, human development, and environmental conditions. Soc Indic Res. 2008; 87(2): 223-36. doi: 10. 1007/s11205-007-9167-6.

12. Premji S, Shakya Y. Pathways between under/unemployment and health among racialized immigrant women in Toronto. Ethn. Health. 2017; 22(1): 17-35. doi: 10.1080/13557858.2016.1180347.

13. Grewal SK, Bhagat R, Balneaves LG. Perinatal beliefs and practices of immigrant Punjabi women living in Canada. J Obstet Gynecol Neonatal Nurs. 2008; 37(3): 290-300. doi: 10.1111/j.1552-6909. 2008.00234.x.

14. University of Saskatchewan. Data and statistics: Canada. [updated 2020 July 22; cited 2020 August 4]. Available from: https://libguides.usask.ca/data-canada.

15. Statistics Canada. Canadian community health survey - annual component (CCHS). [updated 2019 December; cited 2020 August 4]. Available from: https:/www.statcan.gc.ca/eng/survey/household/3226.

16. Statistics Canada. Income highlight tables, 2016 census. Analysis in brief on the internet. [update 2019 February 20; cited 2020 August 4]. Available from: https:/www12.statcan.gc.ca/censusrecensement/2016/dp-pd/hlt-fst/inc-rev/Table.cfm?Lang $=$ Eng $\& \mathrm{~T}=102 \& P R=0 \& D 1=1 \& R P P=$ $25 \& \mathrm{SR}=1 \& \mathrm{~S}=108 \& \mathrm{O}=\mathrm{D}$.

17. University of Saskatchewan. Does my project require human ethics approval?. [updated 2019 August 29; cited 2020 August 4]. Available from: https://wiki.usask.ca/pages/releaseview.action? pageId $=1456046622$.

18. Wong J, Wong S. Cardiovascular health of immigrant women: implications for evidence-based practice. Clin Gov. 2003; 8(2): 112-22. doi: 10.1108/14777270310471595.

19. Oza-Frank R, Narayan KM. Overweight and diabetes prevalence among US immigrants. Am J Public Health. 2010; 100(4): 661-8. doi: 10.2105/AJPH.2008.149492.

20. Sethi B. Exploring newcomer settlement and integration supports in Brantford, and BrantHaldimand-Norfolk Counties: community-based participatory research. Waterloo. Ont: Wilfrid Laurier University; 2009.

\section{Corresponding author}

Yiyan Li can be contacted at: yiyan.li@usask.ca

For instructions on how to order reprints of this article, please visit our website:

www.emeraldgrouppublishing.com/licensing/reprints.htm

Or contact us for further details: permissions@emeraldinsight.com 